\title{
Next step for climate-change analysis
}

Bert Bolin

\section{In this article, the chairman of the Intergovernmental Panel on Climate Change, explains the preparations for the organization's second assessment, to be published in September next year.}

THE Intergovernmental Panel on Climate Change (IPCC) is responsible for the scientific and technical assessment underlying the Framework Convention for Climate Change agreed in June 1992 in Rio de Janeiro. IPCC was created in 1988 by the United Nations Environmental Programme (UNEP) and the World Meteorological Organization (WMO), and its work is partly financed by these organizations and partly by voluntary contributions from various countries.

IPCC's first assessment* in 1990, updated in 1992, analysed the scientific basis for the likelihood and character of climate change during the next century from increasing emissions of greenhouse gases the likely impact of any change in climate; and the strategies that should be devised to adapt to any climate change. The future form of cooperation between IPCC and the convention will be decided at the first meeting of the parties to the convention, to be held next March in Berlin.

Our task is to assess knowledge rather than to recommend measures to be taken. We plan to have completed the next phase of our assessment of the available scientific and technical literature by September next year, when we will produce our "Second Assessment". The main task at Berlin will be to establish a basis for assessing how different countries contribute to the increasing concentrations of greenhouse gases in the atmosphere. Countries will have to adopt common methodologies for computing national emissions, for example, and to agree on a standard form for reporting them. The relative importance of different greenhouse gases will need to be agreed.

It does not seem likely that by 1995 negotiations will have progressed very far on how to achieve the prime goal agreed at Rio, the "stabilization of greenhouse gas concentrations in the atmosphere that would prevent dangerous anthropogenic interference with the climate system". Just what is meant by the word "dange-

*IPCC's first assessment is published as:

Houghton, J. T., Jenkins, G. G. \& Euphraums, J. J. (eds) Climate Change Working Group I. Scientific Assessment Climate Change Working Group
(Cambridge Univ. Press, 1990).

(Cambridge Univ. Press, 1990). Climate Change Working Group II Impacts Assessment (Australian Government Publishing Service, Canberra, 1990).

Bernthal. F. M. (ed.) Climate Change Working Group III. Response Strategies (US Department of State, Washington DC, 1990)

Houghton, J. T., Callander B. A. \& Varney, S. K. (eds) Climate Change 1992. Working Group I. Supplementary Report to the IPCC Scientific Assessment (Cambridge Univ. Press, 1992). rous" needs to be sorted out. IPCC will bring together basic knowledge of relevance in this context, but reaching agreement is a political issue and must therefore be achieved through intergovernmental negotiations within the framework of the convention.

To produce our report by September 1995, we will analyse thousands of scientific papers. Specialists wishing to contribute should submit such material to the most relevant of the working groups whose addresses appear at the end of this article. The lead authors for each section of the report will reflect a balance among different points of view, and will include at least one specialist from a developing country. The lead authors of each working group will identify disparities of view for which there is significant scientific or technical support, and will circulate the first (bulk) draft for peer review. The next stage will be review by government specialists, and the final revisions will be used for preparation of three summaries for policy-makers. The Second Assessment will contain about 50 sections, involving more than 200 contributors.

IPCC's conclusions have been criticized in Nature, other parts of the scientific literature and, to a greater extent, in the popular press, mainly for lack of openness about uncertainties and for brushing aside controversies. Although we did repeatedly emphasize the uncertainties in our present understanding in our earlier reports, we will make further efforts in our next assessment to present the full picture as carefully as possible. We shall be as open as we can be by widely circulating early drafts of our report.

Certainly, the issue of climate change is complex. But although I respect the views of a few scientists who believe that little can be said about future climate based on our present knowledge, I believe that balanced and careful reviews of current knowledge are of great value both to help public awareness and to assist political decision-making. Policy-makers are more likely to seek scientists' advice if scientists are explicity addressing controversies in the scientific literature and attempting to clarify their implications.

An increasing number of semi-popular articles about climate change are being published, some predicting imminent catastrophe and others accusing IPCC of exaggerating future dangers. Many of these articles emanate from special- interest groups, and all are supposedly based on scientific findings. This state of affairs is hardly surprising, and scientists will simply have to pursue good leads in order to arrive gradually at generally agreed interpretations.

More problematic are the popular articles in the daily press, written by people, often well-known in other areas, who do not know much about the basic scientific literature in the field. In my view, it is not possible to resolve key scientific issues in articles aimed at the general public. Although concepts such as global warming or environmental hazards can be easily understood by everybody, the scientific issues cannot so easily be explained. For example, theoretical models of the climate system have been criticized, but any substitute also represents an interpretation of the available information, perhaps using a conceptual model, which is likely to be more primitive than a computer model. Dozens of research groups have devoted hundreds of man-years to models of climate change. It seems to me reasonable that reservations about their results should be supported by thorough analysis. Sadly, too often this is not the case.

As chairman of IPCC, I welcome thorough, critical analyses. But it is essential that such arguments are themselves published so that they can be appraised and used for the IPCC assessment process, thus adding to their credibility.

Bert Bolin is at Kvarnasvagen 6, 18451 Osterskar, Sweden.

Deadline for contributions to the first draft of the Second Assessment is the end of June 1994 Contributions should be supported by reference to peer-reviewed articles and reports available internationally, and with preprints of unpublished material. Finalization of the first draft, peer review and revisions will proceed during the rest of 1994.

Working group I support unit. Scientific assessment of likely future climate changes. Dr Bruce Callender, Meteorological Office, Hadley $\mathrm{Cli}-$ mate Centre, London Road, Bracknell RG12 2ST, UK. Fax + 44344856912

Working group II support unit. Impacts of climate change; means for mitigation and adaptation. Dr Richard Moss, 300 D Street, SW, Suite 840 , Washington, DC 20024, USA. Fax +1 202554 7830.

Working group III support unit. Interdisciplinary issues, particularly integrated socioeconomic analyses. Dr Eric Haites, Environment Canada, La Salle Academy, 373 Sussex Drive, Block E, Ottawa K1A OH3, Canada. Fax +1 416369 0922. 